\title{
The Inflammasome in Liver Injury and Non-Alcoholic Fatty Liver Disease
}

\author{
Wajahat Zafar Mehal \\ Section of Digestive Diseases, Yale University, New Haven, Conn., and Section of Digestive Diseases, Department of \\ Veterans Affairs Connecticut Healthcare, West Haven, Conn., USA
}

\section{Key Words}

Inflammasome · Liver injury · Non-alcoholic fatty liver disease

\begin{abstract}
The liver possesses a strong inflammatory response, as seen experimentally and clinically with liver inflammation due to toxic and metabolic stress, sepsis and ischemia. Initiation of this inflammatory response requires the interaction of two types of extracellular signals which collectively upregulate and activate a cytosolic molecular complex termed the inflammasome. Signal 1 is via activation of pattern recognition receptors, and signal 2 is delivered by diverse stimuli including particulates and adenosine triphosphate. The common end result of inflammasome activation is the activation of the protease caspase- 1 with release of active interleukin-1 $\beta$. The inflammasome is important in a wide range of conditions including alcoholic and non-alcoholic steatohepatitis. Kupffer cells are known to be important, but the consequences of inflammasome activation in other hepatic immune cells have not been well characterized. The inflammasome pathway is also known to be required for a full fibrotic response, as demonstrated by reduced lung, skin and liver fibrosis in inflammasome-deficient mice. Identification of the inflammasome machinery has opened up novel therapeutic avenues by the use of antagonists for Tolllike receptors as well as the adenosine triphosphate receptor $\mathrm{P}_{2} \mathrm{X}_{7}$, and the interleukin-1 receptor. There is now great interest in how inflammasome pathways are regulated. The
\end{abstract}

initial challenge is to understand how an acute inflammatory response is sustained. This is a significant issue as the known stimuli result in an acute response that is self-limited to under $24 \mathrm{~h}$. This suggests that there are significant regulators which allow sustained inflammasome activation in conditions such as non-alcoholic steatohepatitis and alcoholic hepatitis.

(c) 2014 S. Karger AG, Basel

\section{Initiation of Inflammation}

The requirement to have an effective response against invading pathogens is a central function of the immune system. $\mathrm{T}$ - and B-cell activation results in very specific immune responses and takes 2-3 days to mature. In contrast, the innate immune system can respond to pathogens within minutes [1]. Activation of the innate immune system also occurs after tissue injury, in the absence of pathogens, and is termed sterile inflammation. This is bona fide inflammation with accumulation of neutrophils and macrophages, and the production of pro-inflammatory cytokines and chemokines, especially tumor necrosis factor (TNF) and interleukin (IL)- $1 \beta$, as well as reactive oxygen species $[1,2]$. The triggers of sterile inflammation are thought to be self-molecules that are usually hidden from view but are released during nonapoptotic cell death, and are termed damage-associated molecular patterns (DAMPs). Sterile inflammation can

\section{KARGER}

E-Mail karger@karger.com

www.karger.com/ddi (c) 2014 S. Karger AG, Basel

0257-2753/14/0325-0507\$39.50/0
Wajahat Zafar Mehal, MD, PhD

Section of Digestive Diseases

Yale University, TAC S223A

New Haven, CT 06520 (USA)

E-Mail wajahat.mehal@yale.edu 
be induced by many DAMPs including adenosine triphosphate (ATP) and uric acid, which have the ability to activate inflammation in the non-infectious immune response. Many DAMPs have been identified as endogenous factors that can be released or generated into the extracellular environment by dying cells, or by abnormal metabolism, and trigger sterile inflammation under conditions of cellular stress or injury [3]. Examples of DAMPs derived from necrotic cells include intracellular proteins, such as the chromatin-associated protein highmobility group box 1 (HMGB1), heat-shock proteins (HSPs) $[4,5]$, and proteins derived from the extracellular matrix that are generated following tissue injury, such as hyaluronan, heparin sulfate and biglycan. These are generated as a result of proteolysis by enzymes released from dying cells or by proteases activated to promote tissue repair and remodeling [6]. Non-protein DAMPs are released or generated during cell death or purine metabolites, such as ATP and uric acid [7, 8]. Mitochondria are a rich source of DAMPs including mitochondrial DNA, formyl peptides, cytochrome $\mathrm{c}$ and ATP, making them potent stimulators of inflammation $[9,10]$. Mitochondria may have a unique ability to induce inflammation as they can provide the full range of signals required to initiate sterile inflammation. Some biologically active proinflammatory cytokines and chemokines, such as IL-1a and IL-33, can be released by necrotic cells, serve a similar function as conventional DAMPs $[11,12]$. Release of DAMPs is also not limited to cell death, however, as some DAMPS including HMGB1 can be secreted by activated macrophages in response to lipopolysaccharide (LPS), TNF and TGF- $\beta$ [13].

Particulate matter including uric acid crystals, inorganic (silica dioxide), organic (cholesterol), and alum can also induce inflammation $[2,14,15]$. The ability of particulates to induce inflammation seemed like a very limited mechanism found for example in gout, but recent examination of liver tissues from humans and mice has shown that in steatohepatitis, but not simple steatosis, cholesterol crystals are present inside hepatocytes and come into contact with Kupffer cells (KCs) [16]. These crystals are dissolved out under normal processing of tissue specimens which may have resulted in underestimation of their role till now. Additionally, in the rare situations when non-organic particulates such as talc enter the liver there is also a strong fibrotic response [17]. We have also shown that implantation of biomaterials and devices into soft tissues leads to the development of a sterile foreign body response, which can interfere with implant function and eventually lead to failure [18]. For a number of these particles the inflammatory response results in tissue damage and its attendant fibrogenesis can lead to loss of function. Approximately 20 DAMPs have been identified and it is likely that many others are present in vivo (table 1).

\section{Inflammasome Components and Their Activation}

The innate immune system possesses multiple families of germ-line encoded PRRs including the Toll-like receptors (TLRs), NOD-like receptors (NLRs), C-type lectin receptors (CLRs), and several other receptors [19, 20]. Collectively these contribute to immune activation in response to diverse stimuli. Such stimuli include infectious and non-infectious material that can cause tissue damage, and endogenous molecules that are released during cellular injury. Activation of these receptors ultimately leads to the production of cytokines that drive the inflammatory response. DAMPs are the best characterized candidates known to activate PRRs and trigger sterile inflammation. The NLRs are cytosolic pattern recognition receptors and like other innate immune receptor molecules they are involved in sensing the presence of pathogens via PAMPs and endogenous danger by DAMPs. A subset of NLRs forms a complex with ASC (apoptosis-associated speck-like protein a CARD) to activate caspase-1 and induce maturation and secretion of the important pro-inflammatory cytokines IL- $1 \beta$ and IL- 18 . Secretion of these potent inflammatory cytokines directs host responses to infection and injury. Collectively the complex of NLRs, ASC and caspaspe- 1 are termed the inflammasome [21]. These cytosolic inflammasomes have a central role in many diverse inflammatory and fibrotic diseases. In the absence of inflammasome components many disease models fail to develop, and in the setting of sustained inflammasome activation there is spontaneous inflammation and fibrosis [22].

The inflammasome serves as a platform for activation of the cysteine protease caspase- 1 which cleaves the proforms of the cytokines IL- $1 \beta$ and IL-18 to their active and secreted forms. Caspase- 1 also possesses additional functions including regulation of metabolism and unconventional protein secretion [23]. Of the various NLRs, the NLRP3 inflammasome is associated with a wide range of diseases including infectious, auto-inflammatory, and autoimmune disorders [24-26]. The diversity of these triggers suggests that NLRP3 is likely responding to the cellular stress, and may be using the mitochondrial outer membrane as a scaffold. 
Table 1. Alphabetical list of the DAMPs which may be involved in the development of NASH, the type of inflammasome signal they provide, known receptors and proposed therapies

\begin{tabular}{|c|c|c|c|c|}
\hline DAMPs & Signal & Receptor & Therapy & NASH treatment \\
\hline ATP & 2 & $\mathrm{P}_{2} \mathrm{X}_{7}$ & receptor antagonists, apyrase & not known \\
\hline Cytochrome c & 2 & not known & $\gamma$-tocotrienol (GTT) & may be helpful \\
\hline CPS-1 & & not known & not known & not known \\
\hline Defensins & 1 & TLR4, CCR6 & antagonists and antibodies & not known \\
\hline Fatty acids & & TLR4 & none & not known \\
\hline HMGB1 & 1 & TLR4, RAGE & neutralizing antibodies & may be helpful \\
\hline HSP & 1 & TLR4, CD14, CD91 & anti-HSP antibodies & not known \\
\hline Hyaluronic acid & 1 & TLR2, TLR4 & antagonists, hyaluronidase & not known \\
\hline Mitochondrial DNA & 1 & TLR9, NLRP3 & TLR9 antagonists, DNases & may be helpful \\
\hline Nuclear DNA & 1 & TLR9 & TLR9 antagonists, DNases & may be helpful \\
\hline $\mathrm{N}$-formylated peptides & neither & FPR and FPRL1 & antibodies & not known \\
\hline S100 proteins & 1 & RAGE & blocking antibodies & not known \\
\hline Uric acid & 2 & non-receptor & xanthine oxidase inhibitors & not known \\
\hline
\end{tabular}

CPS-1 = Carbamoyl phosphate synthetase 1 ; HSP = heat-shock protein

Caspase- 1 cleaves and activates pro-IL- $1 \beta$ to IL- $1 \beta$ which is a pro-inflammatory cytokine that broadly affects induction of other cytokines, chemotaxis and also enhances the function of other cytokines such as TNF- $\alpha$. IL- $1 \beta$ is synthesized as a pro-protein without a typical signal sequence that would allow its secretion, and instead its cellular release is controlled by caspase-1 [27]. Caspase- 1 is also responsible for the secretion of IL-1a and fibroblast growth factor-2 through an unconventional protein secretion pathway $[23,28]$. Caspase- 1 is constitutively expressed as pro-caspase-1, but it remains inactive in the cytoplasm until inflammatory effector cells such as monocytes and macrophages receive signal 2 (fig. 1). Known activators are changes in the intracellular ionic environment and bacterial products such as LPS and peptidoglycan [28]. Inflammasome machinery recruits pro-caspase-1 either directly through homotypic binding of CARD or indirectly through PYD of ASC protein.

\section{Damage-Associated Molecular Patterns in Non-Alcoholic Steatohepatitis}

The term damage-associated molecular patterns (DAMPs) is applied to any endogenous molecule which is induced by cell damage or stress and results in an inflammatory response [29]. It is worth noting that such molecules are very diverse, not all have a molecular pattern structure, and most do not have anything structur- ally in common with each other (table 1) [30]. Uric acid was one of the initial such DAMPs and this was based on ability of contents from healthy cells to induce inflammation. Interestingly, uric acid needs to be in crystal form to induce inflammation and its mechanism of action is shared with many other particulates such as silica and alum [31]. Such particulates are known to cause a number of inflammatory diseases including gout and pulmonary silicosis. Particulate-based mechanisms had however seemed far from the pathophysiology of non-alcoholic steatohepatitis (NASH). Recently there is accumulating evidence that chronic inhalation exposure to airborne particles $<2.5 \mu \mathrm{m}$ induces macrophage infiltration and unfolded protein response, an intracellular stress signaling in mouse white adipose tissue in vivo [32]. Inhalation of such particles for 6 weeks has also been shown to induce increased inflammation and fibrosis in high-fat diet-induced NASH. In addition, KCs contained the inhaled particles and produced increased levels of inflammatory cytokines [33]. Another potential mechanism of particulate-induced liver inflammation is via cholesterol crystals. The development of intimal inflammation and atheroma formation by cholesterol crystals is via inflammasome activation, and recently cholesterol crystals have been shown to be present in the livers of mice and humans with NASH [16].

Free fatty acids (FFA) are an obvious candidate for initiators of tissue injury and inflammation and NASH. A specific mechanism by which FFA can activate TLR4 has been identified and this requires fetuin- $\mathrm{A}$ which is a 64- 


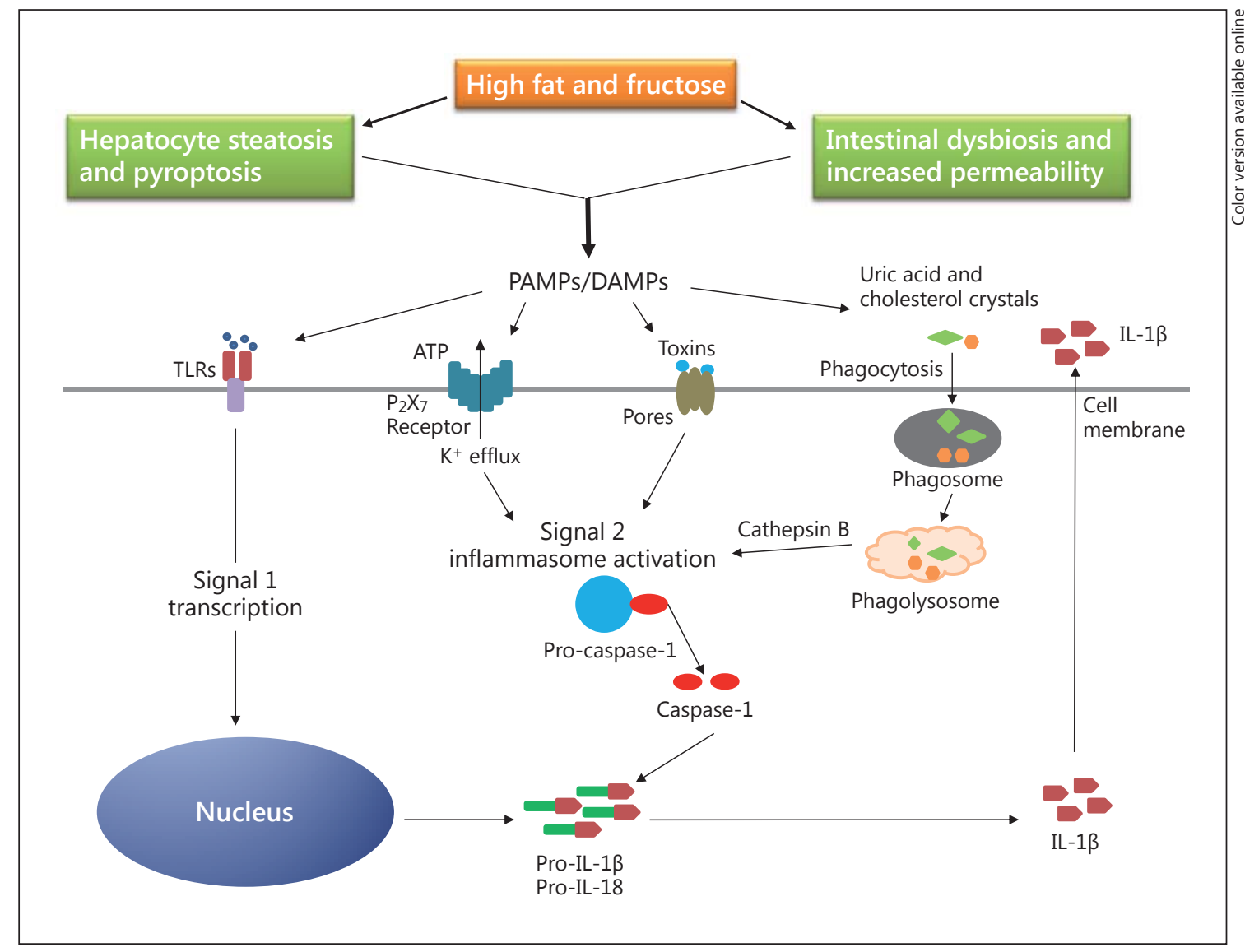

Fig. 1. Inflammasome activation requires two types of signals. Signal 1 results in transcriptional upregulation of Pro-IL- $1 \beta$ and ProIL-18 as well as a number of molecules in the inflammasome machinery. Activation of TLRs and related cytokine receptors are the best known stimulators of signal 1 . Signal 2 results in assembly of the inflammasome machinery in the cytosol and activation of pro- caspase-1. Signal 2 is provided by a very diverse group of stimuli which range from conventional receptor ligand relationships such as the ligand ATP and its receptor $\mathrm{P}_{2} \mathrm{X}_{7}$, to particulates such as cholesterol and uric acid crystals to more diffuse concepts such as reactive oxygen species.
$\mathrm{kDa}$ protein produced almost exclusively by hepatocytes and secreted into the serum [34]. Fetuin-A has a number of important metabolic actions including binding and inhibiting the insulin receptor tyrosine kinase in skeletal muscle and hepatocytes, inhibiting insulin signal transduction and resulting in insulin resistance in these target tissues. These functions are predicted to result in a metabolic syndrome phenotype. In addition to these, fetuin-A has recently been shown to be required for the bulk of the pro-inflammatory response to FFA. In vivo reduction in fetuin-A in mice on a high-fat diet resulted in downregulation of TLR4-mediated inflammatory signaling in adipose tissue, and selective administration of fetuin-A-induced inflammatory signaling. Pro-inflammatory cytokine expression in adipocytes in response to FFA required both fetuin-A and TLR4, and loss of either of them prevented FFA-induced insulin resistance. Fetuin-A was found to directly bind TLR4, and FFA did not produce insulin resistance in adipocytes with mutated TLR 4 or fetuin-A. Collectively this suggests that fetuin-A is a required intermediary for FFA-induced TLR4 stimulation. Fetuin-A levels are elevated in non-alcoholic fatty liver disease (NAFLD), and hepatic expression of fetuin-A correlates with key enzymes in glucose and lipid metabolism [35].

A specific mechanism of palmitic acid-induced steatohepatitis has also been recently identified, and this involves the relatively understudied TLR 2 which is known to be a ligand for hyaluronic acid [6]. Using a cholinedeficient amino acid-defined (CDAA) diet, wild-type 
mice developed profound steatohepatitis and liver fibrosis. In contrast, TLR2-deficient mice had suppressed progression of NASH [36]. Both KCs and hepatic stellate cells (HSCs) respond to TLR2 ligand; however, TLR2 bone marrow chimeric studies demonstrated that KCs were relatively more important than HSCs in TLR2-mediated progression of NASH. The TLR2 ligand palmitic acid induced caspase- 1 activation and release of IL-1a and IL- $1 \beta$ in KCs but not HSCs [36]. Wild-type mice on the CDAA diet showed increased caspase- 1 activation in the liver and elevated serum levels of IL- $1 \alpha$ and IL-1 $\beta$ levels, which were suppressed in TLR2-deficient mice. Further evidence for a role of the inflammasome in NASH comes from an increase in IL- $1 \beta$ protein and mRNA levels in many models of NASH, and the development of steatohepatitis and fibrosis after inflammasome activation $[22,37]$. Lack of IL- $1 \beta$ and the IL-1R results in less steatosis, inflammation and fibrosis in at least two models of NASH $[37,38]$.

A partial list of the DAMPs, their receptors, and the type of signal they provide is listed in table 1. Many DAMPs activate PRR of which TLRs are the best characterized. The function of these receptors is best studied on immune cells, but they are expressed very broadly in the liver with important functions on parenchymal cells [39, 40]. The saturation status of fatty acids is known to be important in their ability to induce inflammation in hepatocytes, with saturated fatty acids enhancing LPS-induced induction of caspase- 1 activation and IL- $1 \beta$ release [41]. This results in release of further DAMPs from hepatocytes resulting in a feed-forward loop which can amplify the inflammatory response [41].

It is likely that IL- $1 \beta$ has a number of roles in the development of NASH. These will include direct metabolic roles such as suppression of peroxisome proliferator-activated receptor- $\alpha$, and also to increase the ability of TNF- $\alpha$ to induce cell death [37]. This ability of IL-1 $\beta$ to increase TNF- $\alpha$-induced cell death is potentially very important for a number of reasons. Firstly it obviates the general criticism that the IL- 1 receptor does not have a death domain and thus IL- $1 \beta$ cannot induce cell death. It may also provide an insight that IL- $1 \beta$ is working in a synergistic manner with other cytokines and signals.

The cell specificity of inflammasome activity has been of great interest and the evidence points towards KCs having a major role. KCs have very high levels of IL-1 $\beta$ mRNA and their depletion reduces total liver IL- $1 \beta$ mRNA and also serum levels of IL- $1 \beta[37,42]$. The IL- $1 \beta$ that is produced by KCs will likely have direct effects on hepatocytes and HSCs (fig. 2). In humans and mice, ex-

The Inflammasome in Liver Injury and NAFLD pression of NLRP3 components is present in the abdominal fat and livers during obesity and this decreases with weight loss [38, 41]. There is however widespread expression of inflammasome components, and bone marrow chimera experiments reveal that a deficiency of IL- $1 \beta$ or IL- $1 \alpha$ results in less diet-induced steatohepatitis and fibrosis [43].

\section{Paradoxical Effects of Loss of Inflammasome Components}

The above data are complex due to the large numbers of DAMPs and DAMP receptors, but conceptually consistent because they fit within the framework of DAMPs activating immune receptors which result in activation of pro-inflammatory pathways including the inflammasome. A significant departure from this framework occurred when it was demonstrated that mice lacking the NLRP6 and NLRP3 inflammasomes had worse progression of NAFLD/NASH and other features of metabolic syndrome [44]. This was due to loss of the normal regulation of the gut microbiota, and remarkably the NASH predisposing phenotype could be transferred to wild-type mice simply by co-housing.

Despite this rather paradoxical result, the mechanism of inflammation fits into the model that has been established with a variety of liver inflammatory conditions including alcoholic hepatitis and NASH. Inflammasome deficiency is associated with changes in the configuration of the gut microbiota resulting in exacerbated hepatic steatosis and inflammation through influx of TLR4 and TLR9 agonists into the portal circulation, leading to enhanced hepatic TNF- $\alpha$ expression that drives NASH progression. Co-housing of inflammasome-deficient mice with wild-type mice results in exacerbation of hepatic steatosis demonstrating that the pathological microbiome when continually entering the gastrointestinal tract of wild-type mice can outcompete the normal microbiome. Once the co-housed animals are separated the wild-type mice revert to the normal microbiome, demonstrating the ability of the normal intestine to control the pathogenic microbiome as long as the latter is not continuously being replenished. Thus, altered interactions between the gut microbiota and the host, produced by defective NLRP3 and NLRP6 inflammasome sensing, can govern the rate of progression of multiple metabolic syndromeassociated abnormalities. This highlights the central role of the microbiota in the pathogenesis of NASH and the obesity phenotype. 


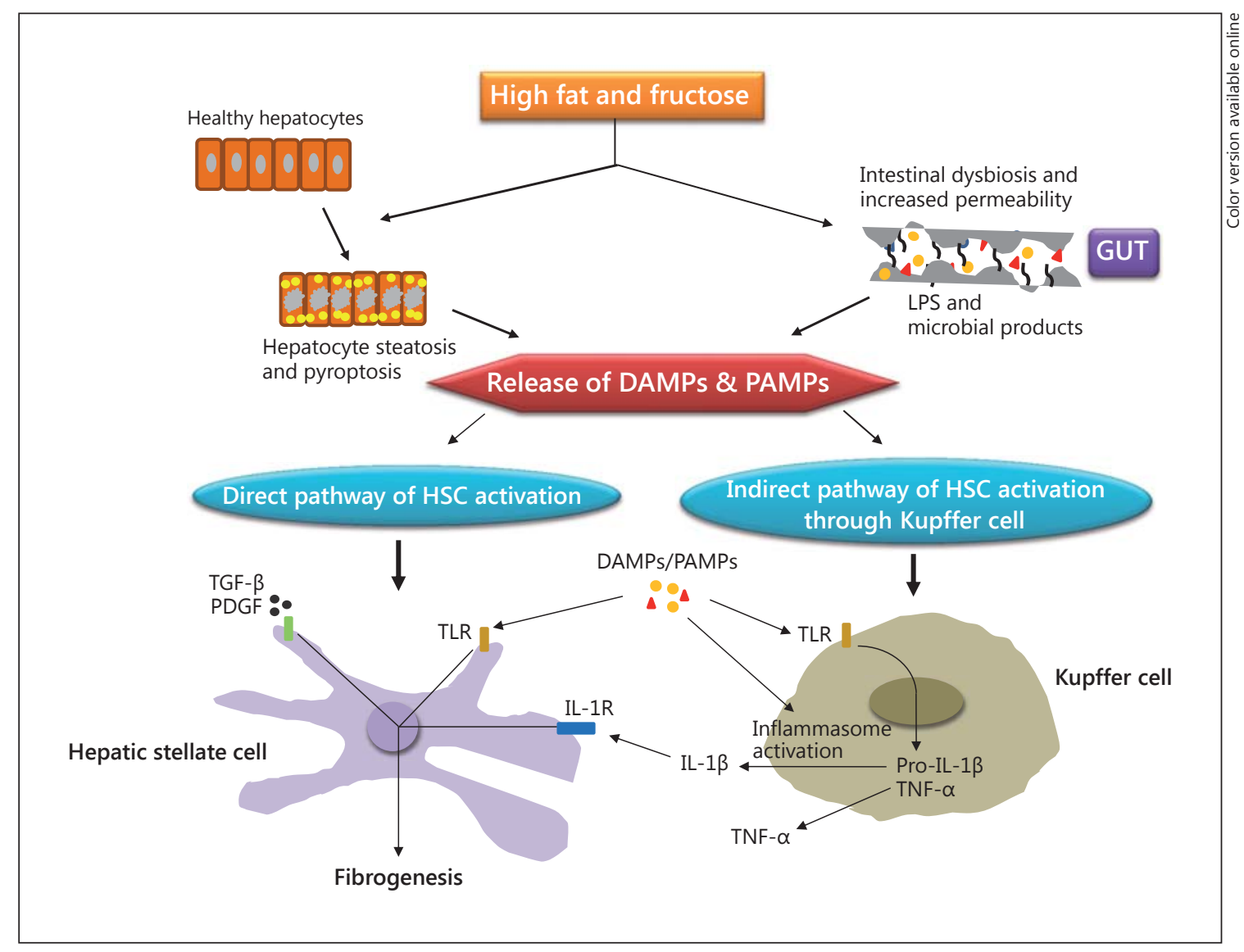

Fig. 2. The source of the majority of signals are hepatocytes (DAMPs) and intestinal luminal contents (PAMPs). Various stresses including metabolic stresses result in hepatocyte damage and release of DAMPs which can then induce activation in KCs and HSCs. In an analogous manner, release of LPS and other mi- crobial products from the lumen to the portal circulation can activate KCs and HSCs. KC activation results in production of IL-1 $\beta$ and TNF- $\alpha$ which can activate HSCs and can also induce hepatocyte death.
These data have revealed an unexpected degree of complexity because the effects of inflammasome activation in the intestinal epithelium will be to limit the outgrowth of pathogenic bacteria and thus be protective; however, activation in the liver is predicted to be proinflammatory. Inflammasome-inhibitory strategies will have to be carefully targeted and monitoring of the microbiome will be an important component.

\section{Acute versus Sustained Activation}

The model of inflammasome activation as outlined above with signals 1 and 2 and depicted in figure 1 is consistent with what we observe with acute inflammasome activation. Many important diseases including NASH, however, are characterized by inflammation over months and years. The above model of inflammasome activation cannot explain these because signal 1 is characterized by rapid (within $18 \mathrm{~h}$ ) tolerance to repeat signals. This is best described for tolerance to LPS and results also in heterotolerance to other TLR agonists. In contrast, stimuli providing signal 2 result in cell death. Recently it has been demonstrated that adenosine via the $\mathrm{A} 2 \mathrm{a}$ receptor can provide a signal to macrophages which results in sustained inflammasome activation [45]. It does this via a cAMP- and PKA-mediated pathway which activates CREB and HIF-1 $\alpha$. One of the consequences of HIF-1 $\alpha$ activation is transcriptional upregulation of pro-IL- $1 \beta$, and thus sustaining signal 1 beyond the typical 18-24 h. Additional consequences are the upregulation of inflammasome components themselves, particularly NLRP3 
and pro-caspase-1. This role of adenosine is strictly dependent on the macrophage having previously received a conventional signal 1 and 2 , and thus seems specifically positioned to sustain this early activity. The role of HIF$1 \alpha$ as a mediator of sustained inflammasome activation is very consistent with the fact that at sites of tissue injury there is frequently hemorrhage and interruption of the blood supply resulting in ischemia. HIF-1a is likely to be upregulated and be driving the inflammasome machinery at a transcription level.

On initial inspection the ability of adenosine to increase IL-1 $\beta$ production seems counter to the vast amount of experimental evidence suggesting adenosine is anti-inflammatory, particularly in relation to inhibition of TNF- $\alpha$ and IL-6 [46]. In this context it is important to note that even in the above setting the adenosine response is selective. LPS-induced TNF- $\alpha$ tolerance is not altered by adenosine [45]. This suggests that the functional consequence of IL- $1 \beta$ production needs to be considered in the context of the cytokine milieu. In the setting of a proinflammatory environment such as high TNF- $\alpha$ and IL$16, I L-1 \beta$ is predicted to enhance the acute inflammatory response. However, in the setting of low TNF- $\alpha$ and IL-6 environment, IL-1 $\beta$ will have a greater role in tissue repair and possibly regeneration.

The identification of the above adenosine-mediated sustained inflammation pathway also provides novel targets for inhibiting the inflammasome. In particular, inhibition of HIF-1a, which has been extensively studied in angiogenesis and tumorigenesis becomes an attractive target. This has taken on clinical expediency due to the recent identification of cardiac glycosides including digoxin as potent inhibitors of HIF-1a [47]. Although the mechanism of digoxin-induced inhibition of HIF-1a is not known, the very large clinical experience with this drug may allow it to be used in early NASH populations and possibly in patients with NASH-induced compensated cirrhosis.

\section{NASH-Induced Fibrosis}

Similar to other chronic inflammatory liver diseases, NASH results in the development of liver fibrosis in a significant number of individuals over time. Liver injury of many etiologies is associated with infiltration of macrophages, which play an important role in regulating initiation, progression, and regression of liver fibrosis [48, 49]. Selective depletion of macrophages during liver injury prevents liver fibrosis [50]. Mice deficient in the macro- phage chemokine axis CCL2-CCR2 have reduced monocyte/macrophage infiltration and are protected from fibrogenesis after chronic liver injury [51-53]. Pharmacological inhibition of hepatic monocyte/macrophage infiltration by blocking CCR2 markedly inhibits liver fibrosis in mice fed a CDAA diet [52]. Macrophages likely stimulate liver fibrosis by producing many pro-fibrotic cytokines and growth factors that induce HSC activation and proliferation (fig. 2) [48, 49]. Among these growth factors is the inflammasome-dependent IL-1 $\beta$. Macrophages also play an important role in promoting liver fibrosis resolution as demonstrated by delayed resolution of liver after deletion of macrophages [50]. This is likely in part through the production of matrix metalloproteinase expression.

In the absence of inflammasome components NLRP3 and ASC, the degree of fibrosis in the liver and other organs is significantly reduced in experimental models [22, $54,55]$. In addition to the liver this is seen in the lung and the skin. A variety of cellular mechanisms may be responsible for this. Some signals such as self-DNA which activates TLR9 can provide signal 1 to inflammasome and also provide a direct fibrogenic signal to liver stellate cells [56]. Such shared signaling suggests an integrated response, and the link is likely to be the release of IL- $1 \beta$ from KCs (fig. 2). Inhibition of a pathway common to both HSCs and KCs such as TLR9 signaling, as well as downstream pathways such as the IL-1 receptor antagonists, hold promise as anti-fibrotic agents. The IL-1R antagonist anakinra has been in clinical use for many years in rheumatoid arthritis, has been shown to reduce liver injury in alcoholic hepatitis, and is an excellent candidate as an anti-fibrotic [57]. Manipulation of the TLR9 pathway is more novel but has progressed to the stage of clinical trials with TLR9 antagonists being used in patients with systemic lupus erythematosus. These agents are candidates as anti-inflammatory and anti-fibrotic agents in $\mathrm{NASH}$ and other liver inflammatory diseases.

\section{Acknowledgements}

This work was supported by a VA Merit award and NIH 2R56DK076674-06.

\section{Disclosure Statement}

The author has no conflicts of interest to disclose. 


\section{References}

$>1$ Chen GY, Nunez G: Sterile inflammation: sensing and reacting to damage. Nat Rev Immunol 2010;10:826-837.

$>2$ Martin P, Leibovich SJ: Inflammatory cells during wound repair: the good, the bad and the ugly. Trends Cell Biol 2005;15:599-607.

-3 Lotze MT, Zeh HJ, Rubartelli A, Sparvero LJ, Amoscato AA, Washburn NR, Devera ME, Liang X, Tor M, Billiar T: The grateful dead: damage-associated molecular pattern molecules and reduction/oxidation regulate immunity. Immunol Rev 2007;220:60-81.

$\checkmark 4$ Scaffidi P, Misteli T, Bianchi ME: Release of chromatin protein HMGB1 by necrotic cells triggers inflammation. Nature 2002;418:191195.

5 Ea HK, Liote F: Calcium pyrophosphate dihydrate and basic calcium phosphate crystal-induced arthropathies: update on pathogenesis, clinical features, and therapy. Curr Rheumatol Rep 2004;6:221-227.

-6 Scheibner KA, Lutz MA, Boodoo S, Fenton MJ, Powell JD, Horton MR: Calcium pyrophosphate dihydrate and basic calcium phosphate crystal-induced arthropathies: update on pathogenesis, clinical features, and therapy. J Immunol 2006;177:1272-1281.

7 Bours MJ, Swennen EL, Di Virgilio F, Cronstein BN, Dagnelie PC: Adenosine 5'-triphosphate and adenosine as endogenous signaling molecules in immunity and inflammation. Pharmacol Ther 2006;112:358-404.

-8 Kono H, Chen CJ, Ontiveros F, Rock KL: Uric acid promotes an acute inflammatory response to sterile cell death in mice. J Clin Invest 2010;120:1939-1949.

$>9$ Krysko DV, Agostinis P, Krysko O, Garg AD, Bachert C, Lambrecht BN, Vandenabeele P: Emerging role of damage-associated molecular patterns derived from mitochondria in inflammation. Trends Immunol 2011;32:157164.

10 Iyer SS, Pulskens WP, Sadler JJ, Butter LM, Teske GJ, Ulland TK, Eisenbarth SC, Florquin S, Flavell RA, Leemans JC, Sutterwala FS: Necrotic cells trigger a sterile inflammatory response through the Nlrp3 inflammasome. Proc Natl Acad Sci USA 2009; 106:2038820393.

-11 Eigenbrod T, Park JH, Harder J, Iwakura Y, Nunez G: Cutting edge: critical role for mesothelial cells in necrosis-induced inflammation through the recognition of IL-1 $\alpha$ released from dying cells. J Immunol 2008;181:81948198.

-12 Moussion C, Ortega N, Girard JP: The IL-1like cytokine IL-33 is constitutively expressed in the nucleus of endothelial cells and epithelial cells in vivo: a novel 'alarmin'? PLoS One 2008;3:e3331.

$>13$ Lotze MT, Tracey KJ: High-mobility group box 1 protein (HMGB1): nuclear weapon in the immune arsenal. Nat Rev Immunol 2005; $5: 331-342$.
14 Duewell P, Kono H, Rayner KJ, Sirois CM, Vladimer G, Bauernfeind FG, Abela GS, Franchi L, Nunez G, Schnurr M, Espevik T, Lien E, Fitzgerald KA, Rock KL, Moore KJ, Wright SD, Hornung V, Latz E: NLRP3 inflammasomes are required for atherogenesis and activated by cholesterol crystals. Nature 2010;464:1357-1361.

15 Mossman BT, Churg A: Mechanisms in the pathogenesis of asbestosis and silicosis. Am J Respir Crit Care Med 1998;157:1666-1680.

16 Ioannou GN, Haigh WG, Thorning D, Savard C: Hepatic cholesterol crystals and crown-like structures distinguish NASH from simple steatosis. J Lipid Res 2013;54:1326-1334.

17 Allaire GS, Goodman ZD, Ishak KG, Rabin L: Talc in liver tissue of intravenous drug abusers with chronic hepatitis. A comparative study. Am J Clin Pathol 1989;92:583-588.

18 West AP, Koblansky AA, Ghosh S: Recognition and signaling by Toll-like receptors. Annu Rev Cell Dev Biol 2006;22:409-437.

19 Kerrigan AM, Brown GD: Syk-coupled Ctype lectin receptors that mediate cellular activation via single tyrosine-based activation motifs. Immunol Rev 2010;234:335-352.

20 Martinon F, Burns K, Tschopp J: The inflammasome: a molecular platform triggering activation of inflammatory caspases and processing of pro-IL- $\beta$. Mol Cell 2002;10:417426.

21 Keller M, Ruegg A, Werner S, Beer HD: Active caspase- 1 is a regulator of unconventional protein secretion. Cell 2008;132:818-831.

22 Wree A, Eguchi A, McGeough MD, Pena CA, Johnson CD, Canbay A, Hoffman HM, Feldstein AE: NLRP3 inflammasome activation results in hepatocyte pyroptosis, liver inflammation, and fibrosis in mice. Hepatology 2013, Epub ahead of print.

23 Kanneganti TD: Central roles of NLRs and inflammasomes in viral infection. Nat Rev Immunol 2010;10:688-698.

24 Franchi L, Eigenbrod T, Munoz-Planillo R, Nunez G: The inflammasome: a caspase-1-activation platform that regulates immune responses and disease pathogenesis. Nat Immunol 2009; 10:241-247.

25 Franchi L, Munoz-Planillo R, Reimer T, Eigenbrod T, Nunez G: Inflammasomes as microbial sensors. Eur J Immunol 2010;40:611615.

26 Nett MA, Cerretti DP, Berson DR, Seavitt J, Gilbert DJ, Jenkins NA, Copeland NG, Black RA, Chaplin DD: Molecular cloning of the murine IL-1 $\beta$ converting enzyme cDNA. J Immunol 1992;149:3254-3259.

27 Kahlenberg JM, Lundberg KC, Kertesy SB, Qu Y, Dubyak GR: Potentiation of caspase-1 activation by the $\mathrm{P}_{2} \mathrm{X}_{7}$ receptor is dependent on TLR signals and requires NF- $\kappa \mathrm{B}$-driven protein synthesis. J Immunol 2005; 175:76117622 .
28 Bauernfeind FG, Horvath G, Stutz A, Alnemri ES, MacDonald K, Speert D, FernandesAlnemri T, Wu J, Monks BG, Fitzgerald KA, Hornung V, Latz E: Cutting edge: NF- $\kappa \mathrm{B}-$ activating pattern recognition and cytokine receptors license NLRP3 inflammasome activation by regulating NLRP3 expression. J Immunol 2009;183:787-791.

29 Matzinger P: Tolerance, danger, and the extended family. Annu Rev Immunol 1994;12: 991-1045.

30 Kono H, Rock KL: How dying cells alert the immune system to danger. Nat Rev Immunol 2008;8:279-289.

31 Shi Y, Evans JE, Rock KL: Molecular identification of a danger signal that alerts the immune system to dying cells. Nature 2003;425: 516-521.

-32 Mendez R, Zheng Z, Fan Z, Rajagopalan S, Sun Q, Zhang K: Exposure to fine airborne particulate matter induces macrophage infiltration, unfolded protein response, and lipid deposition in white adipose tissue. Am J Transl Res 2013;5:224-234.

33 Tan HH, Fiel MI, Sun Q, Guo J, Gordon RE, Chen LC, Friedman SL, Odin JA, Allina J: Kupffer cell activation by ambient air particulate matter exposure may exacerbate non-alcoholic fatty liver disease. J Immunotoxicol 2009;6:266-275.

-34 Ix JH, Sharma K: Mechanisms linking obesity, chronic kidney disease, and fatty liver disease: the roles of fetuin-A, adiponectin, and AMPK. J Am Soc Nephrol 2010;21:406-412.

35 Haukeland JW, Dahl TB, Yndestad A, Gladhaug IP, Loberg EM, Haaland T, Konopski Z, Wium C, Aasheim ET, Johansen OE, Aukrust P, Halvorsen B, Birkeland KI: Fetuin A in nonalcoholic fatty liver disease: in vivo and in vitro studies. Eur J Endocrinol 2012;166:503510 .

-36 Miura K, Yang L, van Rooijen N, Brenner DA, Ohnishi H, Seki E: Toll-like receptor 2 and palmitic acid cooperatively contribute to the development of nonalcoholic steatohepatitis through inflammasome activation in mice. Hepatology 2013;57:577-589.

-37 Miura K, Kodama Y, Inokuchi S, Schnabl B, Aoyama T, Ohnishi H, Olefsky JM, Brenner DA, Seki E: Toll-like receptor 9 promotes steatohepatitis by induction of interleukin- $1 \beta$ in mice. Gastroenterology 2010;139:323-334. e7.

38 De Roos B, Rungapamestry V, Ross K, Rucklidge G, Reid M, Duncan G, Horgan G, Toomey S, Browne J, Loscher CE, Mills KH, Roche HM: Attenuation of inflammation and cellular stress-related pathways maintains insulin sensitivity in obese type I interleukin-1 receptor knockout mice on a high-fat diet. Proteomics 2009;9:3244-3256.

$>39$ Mencin A, Kluwe J, Schwabe RF: Toll-like receptors as targets in chronic liver diseases. Gut 2009;58:704-720. 
40 Dapito DH, Mencin A, Gwak GY, Pradere JP, Jang MK, Mederacke I, Caviglia JM, Khiabanian $\mathrm{H}$, Adeyemi A, Bataller R, Lefkowitch $\mathrm{JH}$, Bower M, Friedman R, Sartor RB, Rabadan R, Schwabe RF: Promotion of hepatocellular carcinoma by the intestinal microbiota and TLR4. Cancer Cell 2012;21:504516.

-41 Csak T, Ganz M, Pespisa J, Kodys K, Dolganiuc A, Szabo G: Fatty acid and endotoxin activate inflammasomes in mouse hepatocytes that release danger signals to stimulate immune cells. Hepatology 2011;54:133-144.

- 42 Stienstra R, Saudale F, Duval C, Keshtkar S, Groener JE, van Rooijen N, Staels B, Kersten S, Muller M: Kupffer cells promote hepatic steatosis via interleukin- $1 \beta$-dependent suppression of peroxisome proliferator-activated receptor- $a$ activity. Hepatology 2010;51:511-522.

43 Kamari Y, Shaish A, Vax E, Shemesh S, Kandel-Kfir M, Arbel Y, Olteanu S, Barshack I, Dotan S, Voronov E, Dinarello CA, Apte RN, Harats D: Lack of interleukin-1 $\alpha$ or interleukin- $1 \beta$ inhibits transformation of steatosis to steatohepatitis and liver fibrosis in hypercholesterolemic mice. J Hepatol 2011; 55:1086-1094.

44 Henao-Mejia J, Elinav E, Jin C, Hao L, Mehal WZ, Strowig T, Thaiss CA, Kau AL, Eisenbarth SC, Jurczak MJ, Camporez JP, Shulman GI, Gordon JI, Hoffman HM, Flavell RA: Inflammasome-mediated dysbiosis regulates progression of NAFLD and obesity. Nature 2012;482:179-185.
5 Ouyang X, Ghani A, Malik A, Wilder T, Colegio OR, Flavell RA, Cronstein BN, Mehal WZ: Adenosine is required for sustained inflammasome activation via the A2a receptor and the HIF-1a pathway. Nat Commun 2013; 4:2909.

46 Chhabra P, Linden J, Lobo P, Douglas Okusa $\mathrm{M}$, Lewis Brayman K: The immunosuppressive role of adenosine A2a receptors in ischemia reperfusion injury and islet transplantation. Curr Diabetes Rev 2012;8:419-433.

47 Zhang H, Qian DZ, Tan YS, Lee K, Gao P, Ren YR, Rey S, Hammers H, Chang D, Pili R, Dang CV, Liu JO, Semenza GL: Digoxin and other cardiac glycosides inhibit HIF-1a synthesis and block tumor growth. Proc Natl Acad Sci USA 2008;105:19579-19586.

48 Ramachandran P, Iredale JP: Macrophages: central regulators of hepatic fibrogenesis and fibrosis resolution. J Hepatol 2012;56:1417-1419.

49 Wynn TA, Barron L: Macrophages: master regulators of inflammation and fibrosis. Semin Liver Dis 2010;30:245-257.

50 Duffield JS, Forbes SJ, Constandinou CM, Clay S, Partolina M, Vuthoori S, Wu S, Lang $\mathrm{R}$, Iredale JP: Selective depletion of macrophages reveals distinct, opposing roles during liver injury and repair. J Clin Invest 2005;115: 56-65.

51 Mitchell C, Couton D, Couty JP, Anson M, Crain AM, Bizet V, Renia L, Pol S, Mallet V, Gilgenkrantz H: Dual role of CCR2 in the constitution and the resolution of liver fibrosis in mice. Am J Pathol 2009;174:1766-1775.
52 Miura K, Yang L, van Rooijen N, Ohnishi H, Seki E: Hepatic recruitment of macrophages promotes nonalcoholic steatohepatitis through CCR2. Am J Physiol Gastrointest Liver Physiol 2012;302:G1310-G1321.

53 Karlmark KR, Weiskirchen R, Zimmermann HW, Gassler N, Ginhoux F, Weber C, Merad M, Luedde T, Trautwein C, Tacke F: Hepatic recruitment of the inflammatory Gr1+ monocyte subset upon liver injury promotes hepatic fibrosis. Hepatology 2009;50:261-274.

54 Artlett CM, Sassi-Gaha S, Rieger JL, Boesteanu AC, Feghali-Bostwick CA, Katsikis PD: The inflammasome activating caspase- 1 mediates fibrosis and myofibroblast differentiation in systemic sclerosis. Arthritis Rheum 2011;63:3563-3574.

55 Watanabe A, Sohail MA, Gomes DA, Hashmi A, Nagata J, Sutterwala FS, Mahmood S, Jhandier MN, Shi Y, Flavell RA, Mehal WZ: Inflammasome-mediated regulation of hepatic stellate cells. Am J Physiol Gastrointest Liver Physiol 2009;296:G1248-G1257.

56 Watanabe A, Hashmi A, Gomes DA, Town T, Badou A, Flavell RA, Mehal WZ: Apoptotic hepatocyte DNA inhibits hepatic stellate cell chemotaxis via Toll-like receptor-9. Hepatology 2007;46:1509-1518.

57 Petrasek J, Bala S, Csak T, Lippai D, Kodys K, Menashy V, Barrieau M, Min SY, Kurt-Jones EA, Szabo G: IL-1 receptor antagonist ameliorates inflammasome-dependent alcoholic steatohepatitis in mice. J Clin Invest 2012;122: 3476-3489. 